\title{
ANÁLISE DAS VARIAÇÕES DO CAMPO TÉRMICO DE SOBRAL (CE): TRATAMENTO GRÁFICO-ESTATÍSTICO DOS DADOS DE TEMPERATURA DOS BAIRROS DA CIDADE
}

\author{
Francisca Nathalia Silva Mesquita ${ }^{(1)}$; Yara Batista Gomes ${ }^{(2)}$; Igor Valério ${ }^{(3)}$; Isorlanda \\ Caracristi ${ }^{(4)}$ \\ 1) Curso de Geografia, Centro de Ciências Humanas (CCH), Universidade Estadual Vale do Acaraú \\ (UVA), Bolsista CNPq, natalia12_2011@hotmail.com \\ 2) Curso de Geografia, Centro de Ciências Humanas (CCH), Universidade Estadual Vale do Acaraú \\ (UVA), Bolsista PBU-UVA, yarabatista70@outlook.com \\ 3) Curso de Geografia, Centro de Ciências Humanas $(\mathrm{CCH})$, Universidade Estadual Vale do Acaraú \\ (UVA), Bolsista PBU-UVA, igoor.valerioo@gmail.com \\ 4) Curso de Geografia, Centro de Ciências Humana $(\mathrm{CCH})$, Universidade Estadual Vale do Acaraú \\ (UVA), Profa. Dra. Orientadora, icaracristi@hotmail.com
}

\section{Eixo: CLIMATOLOGIA EM DIFERENTES NÍVEIS ESCALARES: MUDANÇAS E VARIABILIDADES}

\begin{abstract}
Resumo
Este trabalho tem como objetivo, produzir gráficos e mapas, detalhando as variações do campo térmico do espaço urbano de Sobral (CE), a partir do banco de dados levantados sobre a temperatura dos bairros da referida cidade, auxiliando nas análises da influência da urbanização nos parâmetros de temperatura em ambiente semiárido. Os pressupostos metodológicos contidos em MOREIRA (2003), e no Sistema do Clima Urbano (SCU) proposto por MONTEIRO (1976), como trabalho sobre Urbanização e Conforto Térmico: Análise Climática do Centro da cidade de Sobral - CE de MUNIZ (2016) foi o primeiro trabalho a gerar dados primários de temperatura, umidade e ventos no espaço de Sobral.
\end{abstract}

Palavras-Chave: Ambiente Semiárido; Campo Térmico; Clima Urbano; Transectos Móveis.

\section{Introdução}

Este trabalho tem como objetivo, confeccionar gráficos e mapas, detalhando as variações do campo térmico do espaço urbano de Sobral, a partir do banco de dados levantados sobre a temperatura dos bairros da referida cidade, auxiliando nas análises da influência da urbanização nos parâmetros climáticos em ambiente semiárido. Área de estudo está situada (vide Figura 01) em torno das coordenadas de $3^{0} 41^{\prime}$ de latitude sul e $40^{\circ} 20^{\prime}$ de longitude oeste.

A cidade de Sobral está assentada no vale no médio curso do rio Acaraú, no sertão noroeste cearense, onde o ciclo do algodão provocou intenso desmatamento da caatinga arbórea e hoje a devastação da caatinga arbustiva remanescente continua, favorecendo o aparecimento de manchas de degradação dos solos em torno do perímetro urbano da cidade. 


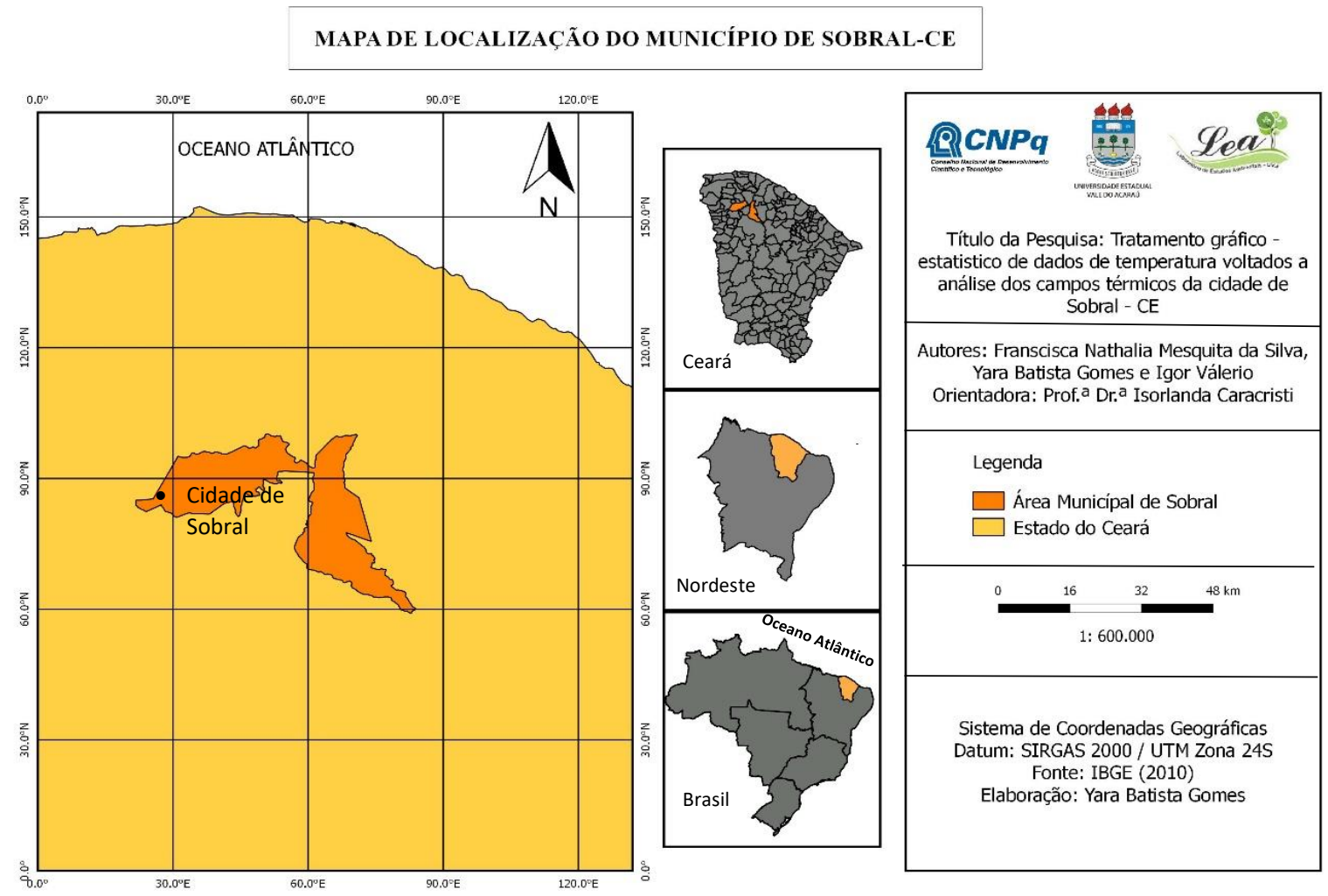

Fonte: Laboratório de Estudos Ambientais, 2016 Fig. 01 - Localização da Cidade de Sobral.

No espaço interurbano as áreas verdes dos sistemas fluviais e lacustres seguem o mesmo ritmo acelerado de degradação, promovida pelas atividades de especulação imobiliária, principalmente na última década. Fatos esses, que veem ocasionando impactos ambientais, dentre eles o aumento da sensação de calor. Por isso, a importância de se estudar as variações do campo térmico ao longo dos bairros da cidade Sobral.

\section{Metodologia.}

Para a efetivação desta pesquisa, foi feita revisão bibliográfica, com foco na verificação de trabalhos sobre a dinâmica atmosférica local/regional e nos estudos de caso de clima urbano de cidades médias. Procedeu-se também o levantamento cartográfico/imagens específicas; treinamento de técnicas estatísticas e gráficas em planilhas digitais e de aplicação de softwares de tratamento de imagens e informações geográficas, conforme MOREIRA (2003), MUNIZ (2016) e de acordo com o Sistema do Clima Urbano (SCU) elaborado por Carlos Augusto Monteiro em 1976, por fim, procedeu-se à tabulação dos dados obtidos por meio da técnica dos 
transectos móveis ao longo de duas rotas/perfis (vide fig. 02) que serviram como amostragem à análise do campo térmico dos bairros da cidade. Em seguida, foram elaborados os gráficos, executadas as análises e cruzamento de dados para a produção de informações visando à relação uso e ocupação dos bairros e as variações no campo térmico.

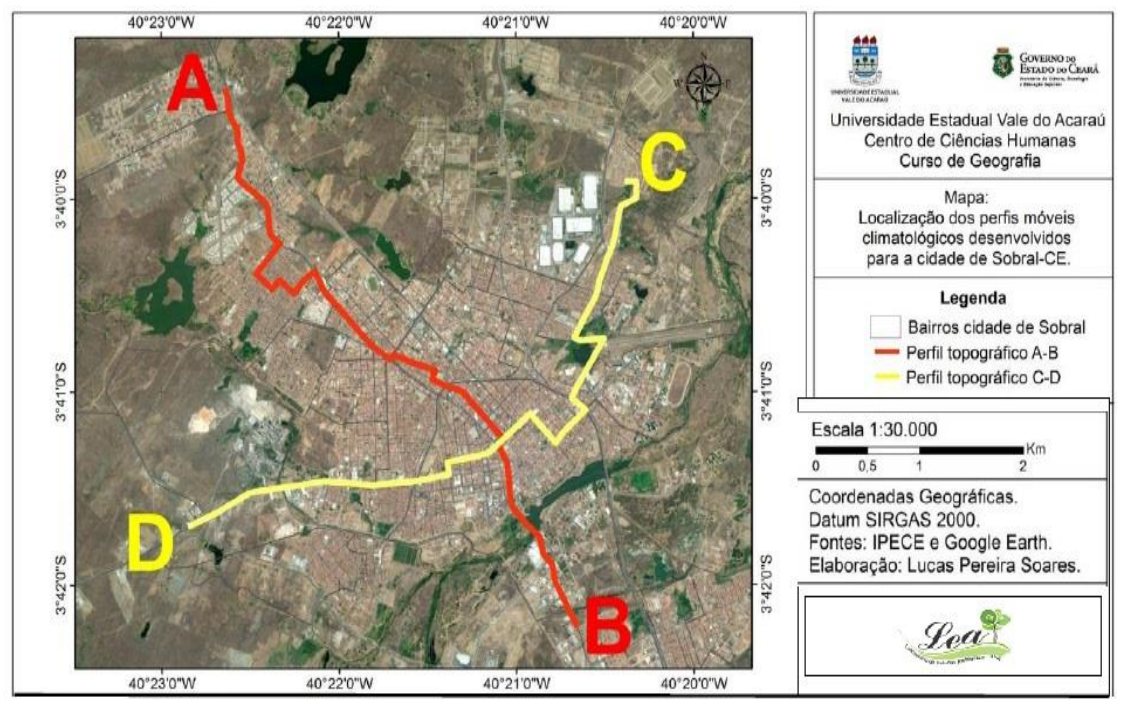

Fig.02. Transectos (Rotas) de coletas de dados de temperatura e umidade na Cidade de Sobral (CE): Rota 01- Perfil A-B (NO-SE) e Rota 02 - Perfil C-D (N-S/ NE- SO) os pontos de observação seguiram a Rota 02. Fonte da imagem base: Google Earth, acesso em 11 de setembro de 2015

Por fim, foram também elaborados e aplicados cinquenta questionários com o intuito de se levantar informações sobre a percepção térmica por parte da população sobralense residente nos bairros em que se levantou os dados de umidade relativa e temperatura do ar por meio dos transectos móveis, sendo os seguintes bairros: Rota A-B (NO-SE) - Renato Parente, Junco, Campo dos Velhos, Centro e Dom Expedito; Rota C-D (N-S/ NE- SO) - Alto da Brasília, Betânia, Centro, Sumaré.

\section{Resultados e Discussões.}

A obtenção de dados climático-ambientais nas referidas rotas foram executadas no período da manhã (às 6h); à tarde (14h); e à noite (19h). O período de coleta de dados de temperatura e umidade no sentido N-S/NE-SO e NO-SE aconteceu no dia 30 outubro de 2015. No período da manhã os instrumentos registraram temperatura média de $26,1^{\circ} \mathrm{C}$ no sentido $\mathrm{N}-\mathrm{S} / \mathrm{NE}-\mathrm{SO}$ e no sentido NO-SE foi registrada a média de $25,4^{\circ} \mathrm{C}$. Essas temperaturas foram registradas em locais com maior vegetação. A umidade, nesse mesmo segmento e período, apresentou-se mais elevada entre $68 \%$ e $67 \%$. Já à noite, registrou-se temperaturas médias amenas de $28^{\circ} \mathrm{C}$ e $27,8^{\circ} \mathrm{C}$, com umidades de $62 \%$ e $63 \%$ nos sentidos NO-S/NE-SO e NO- SE. No período da tarde as maiores temperatura atingiram cerca de $40,5^{\circ} \mathrm{C}$ e $40,6^{\circ} \mathrm{C}$ nos sentidos N-S/NE-SO e NO-SE e as umidades foram de $55 \%$ e $49 \%$. Essas máximas de temperatura aconteceram na Praça de Cuba, que se localiza no Centro comercial da cidade e onde concentra maior 
circulação de pessoas. Com a pesquisa é possível aferir que as temperaturas podem variar de acordo com o local/ambiente e horário mesmo em escala local e microclimática, essas possíveis mudanças podem ser percebidas pelas ações sociais que transformam o espaço natural em um espaço urbanizado e pelo tipo de urbanização não voltada às especificidades de semiaridez.

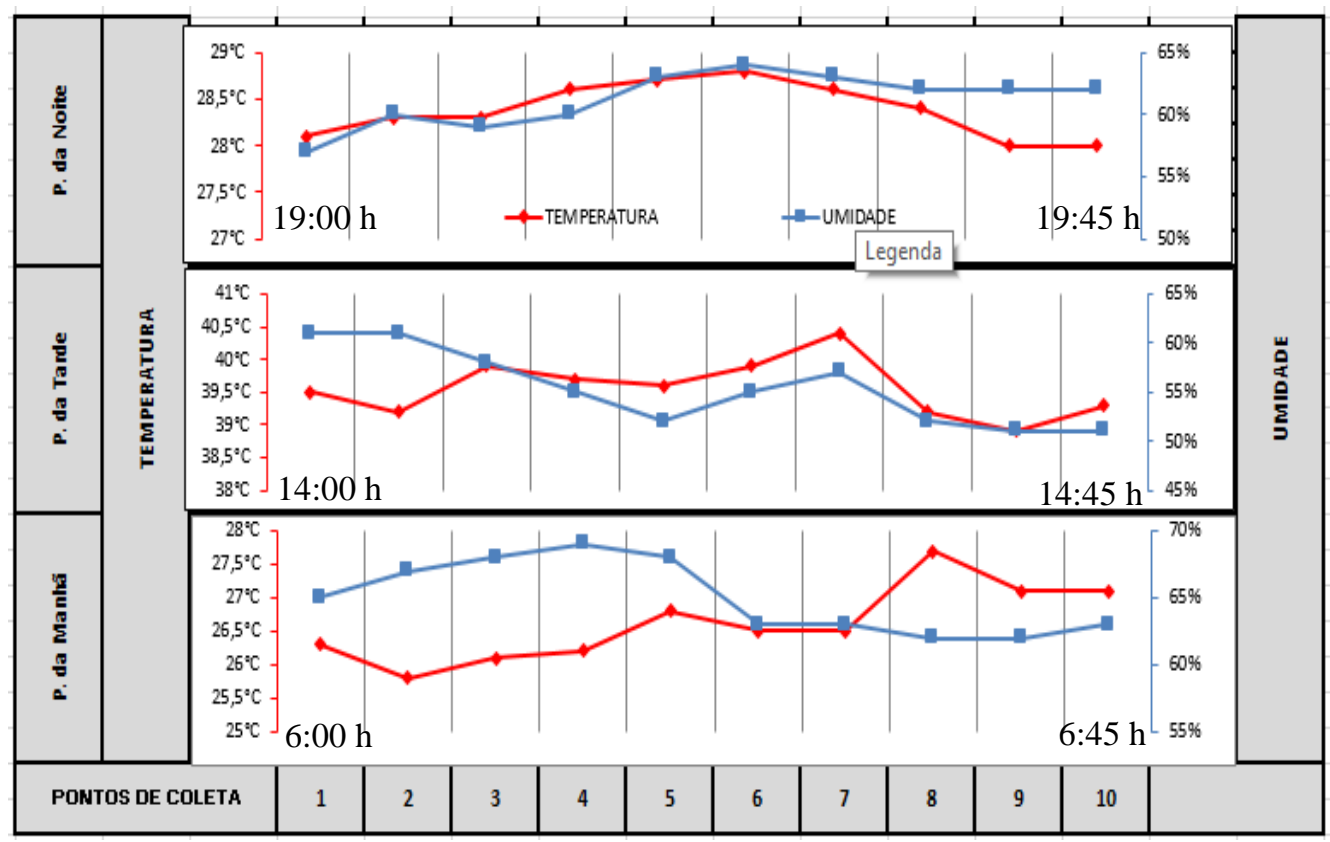

Figura. 03 - Gráfico Preliminar dos dados da $1^{\text {a }}$ Etapa - Estação Seca Rota: Norte-Sul / Nordeste- Sudoeste - Cidade de Sobral (CE), expondo a variação da temperatura e umidade relacionados à coleta que foi realizada nos mês de outubro na cidade de Sobral CE, onde a variação da temperatura está representada pela linha vermelha e a da Umidade pela linha azul. Fonte: Laboratório de Estudos Ambientais, 2016.

É muito importante analisar e compreender os resultados obtidos em campo, que foram incontestáveis, nos experimentos realizados, os elementos climáticos expressaram condições de desconforto na grande maioria das horas, principalmente por se tratar do período seco, que no tipo climático semiárido do nordeste brasileiro, ocorre no segundo semestre, com acentuado déficit hídrico nos meses de outubro, novembro e dezembro. Apesar de todas as mensurações feitas corretamente, o confronto climático dos dados obtidos por meio dos transectos móveis com aqueles resultantes dos questionários, é perceptível a confirmação do desconforto térmico anunciado pela população residente. Os questionários foram aplicados em novembro de 2016 com o intuito de completarmos nossas analises de dados, compreendendo assim a percepção dos sobralenses sobre clima da cidade de Sobral. O gráfico 02 expõe as percepções dos sobralenses sobre as elevadas temperaturas na cidade de Sobral, apenas 12\% dos entrevistados mencionaram que às 13 horas é o período do dia que mais sentem calor. O intervalo com maior percentual foi às 14 horas, com $30 \%$, ou, seja quase $1 / 3$ dos entrevistados sentem muito calor durante esse período, o mesmo é considerado um dos períodos mais críticos, pois a temperatura atinge os um dos mais elevados índices e possuem uma sensação térmica de muito calor, ressalta-se que 
aproximadamente nesse mesmo horário foram registradas as maiores temperaturas na coleta de dados do experimento citado na pesquisa dos transectos moveis. Com 37\%, ao meio dia (12horas) apresentou elevados índices de temperatura, considerados pela população um dos períodos de maior desconforto térmico na cidade de Sobral. Logo em seguida, com 14\%, ás 15 horas foi o segundo mais citado, o mesmo atinge elevados índices de temperatura. De acordo com as respostas dos entrevistados os horários que apresentam um maior desconforto térmico são às 12:00 e 14:00 horas como explicado anteriormente. Esse aumento de desconforto térmico se agrava por diversos fatores, como o tipo de pavimentação que predomina naquele local, a baixa presença de arborização, ausência de corpos d água, áreas com denso fluxo de pessoas e veículos e baixa circulação dos ventos.

\section{Horas que há maior desconforto térmico}

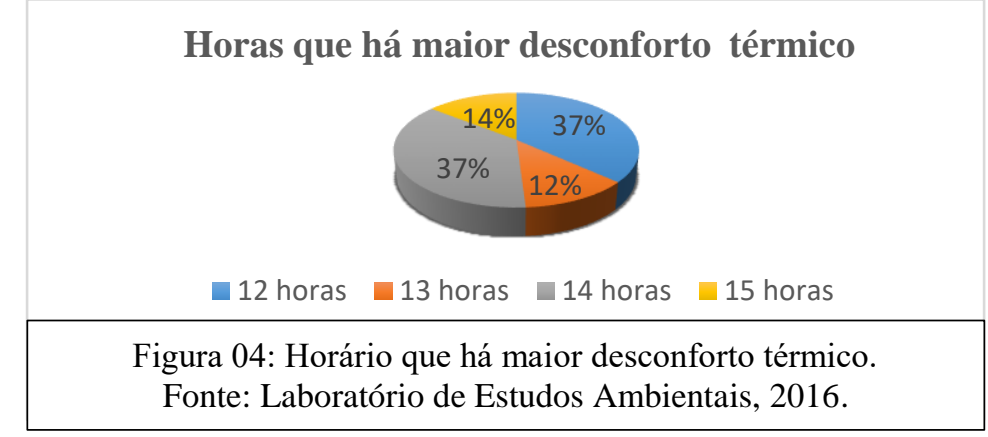

\section{Considerações Finais}

Percebe-se empiricamente que o desenvolvimento da cidade de Sobral (CE) está mudando de forma significativa sua dinâmica ambiental e seu espaço interferindo assim, no fluxo de calor e no conforto térmico consequentemente. Tais transformações ambientais com repercussões climáticas locais e microclimáticas, demonstram a imprescindível necessidade da ampliação e manutenção de áreas verdes, da preservação dos sistemas fluviais e lacustre entre outras ações voltadas ao conforto térmico. Nessa fase do desenvolvimento da pesquisa, já se constatou altas temperaturas acompanhadas de variações interbairros, principalmente naqueles com pouca área verde e maior adensamento de casas. O planejamento e gestão urbanas, apoiados na perspectiva da melhoria da qualidade socioambiental de seus habitantes, requerem uma base de conhecimento científico e os estudo geográficos do clima, tais como executados na presente pesquisa pode contribuir efetivamente.

\section{Bibliografia}

MENDONÇA, F. e MONTEIRO, C.A.F. (orgs.). Clima Urbano - São Paulo, Contexto, 2003.

MONTEIRO, Carlos Augusto de F. Teoria e Clima Urbano - São Paulo, IGEOUSP, Série "Teses e Monografias", nº 25, 1976.

MUNIZ, Fco. Gerson L. Urbanização e conforto térmico: análise climática do centro da cidade de Sobral - CE. 2016. 229f. Dissertação (MAG-UVA) - CCH, Universidade Estadual Vale do Acaraú-UVA, 03/02/2016, Sobral, 2016.

Os autores agradecem ao CNPq e ao Laboratório de Estudos Ambientais (LEA/UVA). 